\title{
SEVERAL FACTORS ASSOCIATING WITH CONTACT DERMATITIS ON OIL PALM PLANTATIONS WORKERS IN BELUTU VILLAGE, KANDIS SUBDISTRICT IN 2016
}

\author{
Muhamadiah \\ Program Studi Magister Ilmu Kesehatan Masyarakat STIKES Hang Tuah Pekanbaru \\ e-mail:muhamadiah89@gmail.com
}

\begin{abstract}
Contact dermatitis is skin infection occurring because of allergen and irritant material. Data of Kandis Health Center show 389 cases of dermatitis, 97 cases among cases of dermatitis are oil palm plantation workers living in Belutu Village. The objective of research is to detect factors associating with contact dermatitis on oil palm plantations workers in Belutu Village.

Method: The design type of occurrence research is case control study. Population of cases is 97 workers suffering from contact dermatitis and population of control is 1235 workers who are not suffering from contact dermatitis. Based on case control study in which one cases and two control, significant level of 5\%, power of test $90 \%$, it is 81 cases and 162 controls taken from each population by systematic random sampling. Analysis of data consists of one variable, two variables, and multiple logistic regressions analysis.

Result: chemical contact (CI 95\% OR: 1,34 - 4,12), without Personal Protective Equipment (PPE) (CI 95\% OR: 1,110-3,405), poor Personal hygiene CI 95\% OR: 1,087-3,415), associating with contact dermatitis.

Conclusion: chemical contact, without using PPE, and poor personal hygiene effect the occurrence of contact dermatitis on oil palm plantations workers in Belutu Village. Recommendation is to avoid chemical contact, use PPE and improve personal hygiene. Suggestion formulated based on the recommendation.
\end{abstract}

Keywords: Occupational diseases, contact dermatitis, chemical contact, using PPE and personal hygiene.

\section{PENDAhULUAN}

Dermatitis kontak adalah peradangan kulit akibat kontak langsung dengan bahan allergen dan iritan. Dermatitis memiliki gejala berupa peradangan kulit dengan ciri - ciri seperti: rasa gatal, kemerahan (eritema), bengkak (edema), tonjolan padat (papul), dan tonjolan berisi cairan (vesikel) (Taylor, 2006). Penyakit akibat kerja telah dikenal dan diketahui sejak lama, termasuk penyakit kulit akibat kerja yang biasa disebut occupational dermatitis. Penyakit kulit akibat kerja merupakan sebagian besar dari penyakit akibat kerja pada umumnya dan di perkirakan $50-75 \%$ dari seluruh penyakit akibat kerja (Sulaksmono, 2006).

Data di Dinas Kesehatan Kabupaten Siak, menunjukkan bahwa pada tahun 2013 penyakit dermatitis masuk kedalam 10 penyakit terbanyak, yaitu 6.572 orang $(6.46 \%)$. Kemudian pada tahun 2014, terjadi penurunan jumlah penderita Dermatitis, yaitu sebanyak 4.339 orang. Namun penyakit Dermatitis masih termasuk kedalam daftar 10 Penyakit terbanyak. (Profil Dinkes Kabupaten Siak, 2013 dan 2014).
Data dari Puskesmas Kandis kabupaten Siak Tahun 2015, Jumlah Penderita Dermatitis adalah 438 orang (Puskesmas Kandis tahun 2015). Kemudian dari bulan Januari hingga Juni tahun 2016, Jumlah penderita Dermatitis sebanyak 389 orang. Hasil observasi dokumen laporan LB01 tahun 2016, dari 389 orang penderita dermatitis, 97 orang adalah pekerja yang bekerja di kebun sawit yang tinggal di Kelurahan Belutu. (Puskesmas Kandis tahun 2016).

\section{METODOLOGI PENELITIAN}

Desain Penelitian ini menggunakan Studi Kasus Kontrol (Case Control Study) (Lapau 2013). Populasi Kasus yang berdomisili di kelurahan belutu adalah pekerja kebun sawit yang menderita dermatitis kontak yang datanya ada dalam laporan LB01 Puskesmas Kecamatan Kandis dari januari 2016 hingga Juni 2016 yaitu sebanyak 97 orang. Sedangkan kontrol adalah pekerja kebun sawit yang tidak menderita dermatitis kontak di kelurahan belutu yaitu sebanyak 1235 orang. Perhitungan besar sampel dengan menggunakan rumus 1 kasus dan 2 kontrol dimana: $\alpha 5 \%, \beta 10 \%, \mathrm{k}=2$ (Ariawan 
1998). didapatkan 81 kasus dan 162 kontrol yang di ambil dari masing masing populasi .

Pengambilan masing - masing sampel secara systematic random sampling. jenis data primer dikumpulkan melalui wawancara terstruktur dengan menggunakan kuesioner yang berisi pertanayan tertutup. Pengolahan data dilakukan dalam tahap editing,coding, cleaning dan tabulating. Analisis data yang dilakukan yaitu analisis univariat, bivariat dengan uji chi square dan analisis multivariat yaitu multiple logistic regresion.

\section{HASIL DAN PEMBAHASAN \\ Hasil}

\section{Analisis Univariat}

Berdasarkan hasil analisis univariat didapatkan hasil sebagai berikut: Pekerja yang Kontak dengan Bahan Kimia yaitu 104 orang (42,8\%), Pekerja yang Tidak Menggunakan Alat Pelindung Diri (APD) yaitu 120 orang (49,4\%), pekerja yang Personal Hygienenya tidak baik yaitu 134 orang $(55,1 \%)$, pekerja yang memiliki masa kerja $\leq 2$ tahun yaitu 119 orang $(49 \%)$, dan pekerja yang berumur $>30$ tahun yaitu 127 orang $(52,3 \%)$

\section{Analisis Bivariat}

Variabel yang berhubungan signifikan dengan Dermatitis Kontak adalah Variabel Kontak Kimia $(p$-value $=0,007)$, Penggunaan APD (p-value $=0,021)$, dan Personal Hygiene ( $\mathrm{p}$-value $=0,028)$. Sedangkan variabel yang tidak berhubungan adalah variabel Masa Kerja dan Umur. (lihat Tabel 1))

\section{Analisis Multivariat}

Seleksi bivariat dilakukan untuk mengetahui variabel mana yang dapat masuk dalam pemodelan multivariat. Variabel yang dijadikan kandidat multivariat adalah kontak kimia, penggunaan APD, Personal Hygiene dan Masa kerja. Setelah mengeluarkan satu persatu variabel yang mempunyai $p$ value terbesar, dan pemeriksaan confounding (apabila ada perubahan OR $>10 \%$ ) maka pemodelan multivariat akhir memperlihatkan variabel Kontak Kimia memiliki nilai OR terbesar. Dalam hal ini kontak kimia merupakan variabel yang paling besar pengaruhnya terhadap kejadian Dermatitis Kontak. Selanjutnya variabel yang mempunyai hubungan terhadap kejadian Dermatitis Kontak berturut-turut adalah Penggunaan APD dan Personal Hygiene. (lihat tabel 2)

Tabel 1

Hubungan Beberapa Variabel Independen dengan Kejadian Dermatitis Kontak pada Pekerja Kebun Sawit di Kelurahan Belutu Kecamatan Kandis Tahun 2016

\begin{tabular}{|c|c|c|c|c|c|c|c|}
\hline \multirow[b]{2}{*}{ Variabel } & \multirow[b]{2}{*}{ Kategori } & \multicolumn{2}{|c|}{ Kasus } & \multicolumn{2}{|c|}{ Kontrol } & \multirow[b]{2}{*}{$\begin{array}{l}\mathrm{P} \\
\text { Value }\end{array}$} & \multirow{2}{*}{$\begin{array}{l}\text { OR } \\
(95 \% \\
\text { CI) } \\
\end{array}$} \\
\hline & & $\mathbf{N}$ & $\%$ & $\mathbf{N}$ & $\%$ & & \\
\hline \multirow{4}{*}{$\begin{array}{l}\text { Kontak } \\
\text { Bahan } \\
\text { Kimia }\end{array}$} & Kontak & 45 & 55,6 & 59 & 36,4 & \multirow{4}{*}{$\mathbf{0 , 0 0 7}$} & \multirow{4}{*}{$\begin{array}{l}2,182 \\
(1,268 \\
- \\
3,755)\end{array}$} \\
\hline & Tidak & 36 & 44,4 & 103 & 63,6 & & \\
\hline & Kontak & & & & & & \\
\hline & Total & 81 & 100 & 162 & 100 & & \\
\hline \multirow{5}{*}{$\begin{array}{l}\text { Penggunaan } \\
\text { APD }\end{array}$} & $\begin{array}{l}\text { Tidak } \\
\text { Pakai }\end{array}$ & 49 & 60,5 & 71 & 43,8 & \multirow[t]{5}{*}{0,021} & \multirow{5}{*}{$\begin{array}{l}1,963 \\
(1,140 \\
- \\
3,378)\end{array}$} \\
\hline & APD & & & & & & \\
\hline & Pakai & 31 & 39,5 & 91 & 56,2 & & \\
\hline & APD & & & & & & \\
\hline & Total & 81 & 100 & 162 & 100 & & \\
\hline \multirow{4}{*}{$\begin{array}{l}\text { Personal } \\
\text { Hygiene }\end{array}$} & Tidak & 53 & 65,4 & 81 & 50 & \multirow[t]{4}{*}{0,028} & \multirow{4}{*}{$\begin{array}{l}1,893 \\
(1,090 \\
- \\
3,287) \\
\end{array}$} \\
\hline & Baik & & & & & & \\
\hline & Baik & 28 & 34,6 & 81 & 50 & & \\
\hline & Total & 81 & 100 & 162 & 100 & & \\
\hline \multirow[t]{3}{*}{ Masa Kerja } & $\leq$ & 46 & 56,8 & 73 & 45,1 & \multirow[t]{3}{*}{0,112} & \multirow{3}{*}{$\begin{array}{l}1,602 \\
(0,395 \\
- \\
2,743)\end{array}$} \\
\hline & $>2$ tahun & 35 & 43,2 & 89 & 54,9 & & \\
\hline & Total & 81 & 100 & 162 & 100 & & \\
\hline \multirow[t]{4}{*}{ Umur } & $>30$ & 43 & 53,1 & 84 & 51, & \multirow[t]{4}{*}{0,964} & \multirow{4}{*}{$\begin{array}{l}1,051 \\
(0,616 \\
-1,793\end{array}$} \\
\hline & Tahun & & & & & & \\
\hline & $\leq 30$ & 38 & 46,9 & 78 & 48,1 & & \\
\hline & Total & 81 & 100 & 162 & 100 & & \\
\hline
\end{tabular}

Tabel 2

Hasil Analisis Multivariat (Pemodelan

\begin{tabular}{lcccc} 
& \multicolumn{3}{c}{ Akhir) } & \\
\hline \multicolumn{1}{c}{$\begin{array}{l}\text { Variabel } \\
\text { Independen }\end{array}$} & $\begin{array}{c}\text { P } \\
\text { Value }\end{array}$ & OR & \multicolumn{2}{c}{$\mathbf{9 5 \%}$ CI For EXP } \\
\cline { 4 - 5 }
\end{tabular}

\section{Pembahasan}

Kontak Kimia

Dalam penelitian ini ditemukan bahwa ada hubungan sebab akibat antara Kontak Kimia dengan kejadian Dermatitis Kontak. pekerja kebun sawit yang saat bekerja ada kontak dengan bahan kimia lebih beresiko 2,35 kali untuk menderita dermatitis kontak dibandingkan dengan pekerja kebun sawit yang saat bekerja tidak kontak dengan bahan kimia. Ditemukan dalam teori bahwa Kontak kimia merupakan faktor yang sering menjadi penyebab dermatitis kontak. Dermatitis kontak iritan dan alergi terjadi akibat salah satu bagian 
tubuh pekerja terpapar atau kontak dengan bahan seperti asam dan garam zat kimia anorganik, persenyawaan kimia organik hidrokarbon, pelarut, oli, ter, zat warna dan lainnya (Tur,E 2007). Hal ini sejalan dengan Hasil Penelitian Maharwiarti (2014) yang menjelaskan bahwa kontak kimia mempunyai hubungan bermakna dengan kejadian dermatitis kontak pada pekerja.

Berdasarkan hasil penelitian ini direkomendasikan supaya tidak terjadi dermatitis kontak pada pekerja kebun sawit maka pekerja kebun sawit menghindari kontak dengan bahan kimia saat bekerja. Untuk itu pekerja disarankan menggunakan APD lengkap saat bekerja dan mendapatkan pelatihan tentang teknik penggunaan bahan kimia (pupuk dan herbisida) saat bekerja.

\section{Penggunaan APD}

Dalam penelitian ini ditemukan bahwa ada hubungan sebab akibat antara Penggunaan APD dengan Kejadian Dermatitis kontak. pekerja kebun sawit yang tidak menggunakan APD saat bekerja lebih beresiko 1,94 kali untuk menderita Dermatitis Kontak dibandingkan dengan Pekerja Kebun Sawit yang menggunakan APD saat bekerja. Ditemukan teori bahwa Penggunaan pakaian dan Alat pelindung diri merupakan upaya preventif dalam pencegahan dermatitis kontak. (Suma'mur, 2013). Pekerja yang selalu menggunakan sarung tangan dengan tepat akan menurunkan terjadinya dermatitis kontak akibat kerja baik jumlah maupun lama perjalanan dermatitis kontak (Cahyawati, 2011).

Hal ini sejalan dengan hasil penelitian yang dilakukan oleh cahyawati (2011) dan wintoko (2013) bahwa penggunaan APD mempunyai hubungan bermakna dengan kejadian dermatitis kontak pada pekerja.

Berdasarkan hasil penelitian ini direkomendasikan supaya tidak terjadi kontak langsung dengan bahan kimia pada pekerja kebun sawit, maka pekerja kebun sawit harus menggunakan APD lengkap saat bekerja. untuk itu pekerja disarankan agar menyediakan APD, mendapatkan pelatihan atau penyuluhan tentang pentingnya menggunakan APD saat bekerja.dan menerapkan budaya tentang kesadaran akan pentingnya menggunakan APD saat bekerja.

\section{Personal Hygiene}

Dalam penelitian ini ditemukan bahwa ada hubungan sebab akibat antara Personal Hygiene dengan kejadian Dermatitis kontak. Pekerja Kebun Sawit yang Personal Hygiene nya tidak baik lebih beresiko 1,92 kali untuk menderita Dermatitis Kontak dibandingkan dengan Pekerja Kebun Sawit yang Personal Hygiene nya baik. Personal Hygiene yang buruk menyebabkan dermatitis, karena menjadi faktor pendukung agen penyebab untuk memperparah kejadian dermatitis (cahyawati,2011).

Penelitian ini sejalan dengan penelitian cahyawati (2011) dan Wintoko (2013) bahwa ada hubungan signifikan antara personal hygiene dengan kejadian Dermatitis Kontak pada pekerja.

Berdasarkan hasil penelitian ini direkomendasikan supaya tidak terjadi dermatitis kontak pada pekerja kebun sawit maka pekerja kebun sawit untuk memperbaiki personal hygienenya. Untuk itu disarankan agar dilakukan water treatment pada sumber air untuk mandi sebelum di alirkan ke rumah pekerja dan pekerja mendapatkan penyuluhan tentang personal hygiene dan Perilaku Hidup Bersih dan Sehat (PHBS).

\section{KESIMPULAN}

Variabel yang mempengaruhi kejadian dermatitis kontak pada pekerja kebun berturutturut adalah kontak kimia 2,35 (CI 95\% OR = 1,34 - 4,12), penggunaan APD 1,94 kali (CI $95 \% \mathrm{OR}=1,110-3,405)$ dan personal hygiene 1,92 kali (CI 95\% OR = 1,087 - 3,415). Tidak ada variabel yang confounding. Variabel yang tidak memiliki hubungan signifikan dengan kejadian dermatitis kontak pada pekerja kebun sawit adalah masa kerja dan umur.

\section{DAFTAR PUSTAKA}

Ariawan, I (1998), Besar dan Metode Sampel pada Penelitian Kesehatan, Jurusan Biostatistik dan Kependudukan FKM: UI, Depok: Jakarta 
Cahyawati, dkk, (2011), Faktor yang berhubungan dengan Kejadian Dermatitis pada Nelayan, Jurnal Kesehatan Masyarakat: e-journal Universitas Negeri Semarang. http://journal.unnes.ac.id/index.php/kem as (diakses pada 10 januari 2016).

Dinkes Siak (2013), Profil Dinas Kesehatan Kabupaten Siak, Siak, (2014), Profil Dinas Kesehatan Kabupaten Siak, : Siak,

Lapau, B (2013). Metode penelitian kesehatan. DKI Jakarta: Yayasan Pustaka Obor Indonesia.

Lestari, F, (2007), Faktor - faktor yang berhubungan dengan dermatitis kontak pada pekerja di PT Inti Patja Press Industri, Makara Kesehatan, Vol.11, No. 2

Maharwiarti, A (2014), Faktor - faktor yang berhubungan dengan Kejadian Dermatitis Kontak Alergi di Puskesmas Tapa Kabupaten Bone Bolango. Jurusan Keperawatan, Fakultas Ilmu - ilmu Kesehatan: Universitas Negri Gorontalo, Wintoko,dkk(2013). Faktor - Faktor yang Mempengaruhi Kejadian Dermatitis
Kontak Akibat Kerja Pada Karyawan Pencucian Mobil Di Kelurahan Sukarame Kota Bandar Lampung, Medical Journal of Lampung University, Vol. 3 No. 3

Puskesmas Kandis ( 2015), Laporan LB 01 Puskesmas Kandis: Kandis (2016), Laporan LB 01 Puskesmas Kandis: Kandis

Suma'mur, (2013), Higiene Perusahan dan Kesehatan Kerja (Hiperkes), Jakarta; CV. Sagung Seto.

Sulaksmono, M. (2006) Keuntungan dan kerugian patch test (uji tempel) dalam upaya menegakan diagnosa penyakit kulit akibat kerja (occupational dermatosis).Surabaya: Fakultas Kesehatan Masyarakat Universitas Airlangga;

Taylor JS, dkk. (2008) Occupational skin diseases due to irritans and allergens. Dalam: Fitzpatricks et al, editors. Dermatology in general medicine vol.2 7 th ed. New York: Mc Graw Hill Medical;.p.2067-2073

Tur, E (2007), Environmental Factors in Skin Diseases, Basel (Switzerland); S. Karger AG 